\title{
ABOUT A QUESTION OF A DECREASE OF A ROCK PRESSURE AT AN ORE DRAWING FROM THE BROUGHT DOWN BLOCKS \\ Shepel O.L
}

PhD (Engineering), associated professor of the Department of Underground Mining of Mineral Deposits, Kryvyi Rih National University, 11 Matusevych St., 50027 Kryvyi Rih, Ukraine

\section{Rymarchuk B.I.}

DSc (Engineering), Senior Scientific Associate (Engineering), professor of the Department of Underground Mining of Mineral Deposits, Kryvyi Rih National University, 11 Matusevych St., 50027 Kryvyi Rih, Ukraine

Purpose. The analysis of researches efficiency of an ore drawing, as basic process of underground mining operations at mining methods of a sublevel caving of ore and adjacent strata which provide improvement of parameters of an ore drawing is the purpose of the given operation.

Methodology. The detailed analysis and researches of domestic experience of release of the brought down ore from panels and the blocks, which actual for present time; analytical researches of process of an ore drawing on all plane of the block at horizontal contact between ore and leaning soils and absence of a strong rock pressure on development workings; ore drawing experimental researches in laboratory conditions on models as much as possible approached to real conditions; program methods for processing of results of experiments.

Object of research. Law of change of pressure of broken-down rocks on the block bottom is established at mining of thick steeply dipping deposits of the big prodeleting.

Research conclusion. The effective way and a preparation order, a location and section of developments are offered. On the basis of the executed laboratory researches of an ore drawing in the separate block located the long side an across the strike of a deposit, the size and character of distribution of pressure of broken-down rocks on the bottom basically depends on the sizes of the block along the strike. With increase in the size of the block along the strike increases not only absolute size of pressure, but also non-uniformity of its distribution.

Introduction. Thanks to practical data of mining of ore deposits, it is known, that an ore is drawing - one of the important operations of mining methods floor and a sublevel caving on which depend, both qualitative, and quantitative results of extraction. Therefore, im- 
provement of technologies of working of deposits which provide improvement of parameters of an ore drawing is an actual scientific and technical problem.

Analysis of recent studies and publications. Deep analysis of a problem shows, that earlier on the bottom of blocks at release of broken ore scientists were not engaged in questions of a decrease of a rock pressure. But it is established, that the lowest losses and dilution will turn out at horizontal contact of a surface of the brought down ore to lowered baring's, the minimum distance between exits of cone raises on an undercut level and a uniform ore drawing from all hatches. However practically to create such conditions for release it is possible seldom, owing to difficulty of their simultaneous performance and consequently the question usually should be solved compromise by $[1,2]$.

Release on all area of the block at horizontal contact between ore and settling soils and absence of a strong rock pressure on development workings below an undercut level usually happens, let us assume, under following conditions: 1) at the small area of deposits developed by one block; 2) at an extraction of blocks cut in a cranch or ore and soils (in such conditions half of blocks in chessboard order their extractions is developed, and also a part of blocks and at their consecutive extraction; 3) in some cases at an extraction of blocks only one lateral face, adjoining a goaf, in particular it can be admissible at moderate power of a deposit with the vertical or very abrupt pitch angle, lying down in more or less steady adjoining rocks and developed blocks the in width on all power; 4) at an extraction of blocks and the several sides adjoining a goaf, but at small their horizontal sizes.

Usually on development workings simultaneous release is made for pressure decrease on a part of the area of the block at inclined contact between ore and soils.

The size of a corner of an inclination of contact changes in limits from 30 to 70 degrees, but on the average prevails 45-60 degrees [3].

With increase in this corner of an inclination pressure upon development workings goes down, but simultaneously with it losses and ore dilution increase. The ore drawing is made in regular intervals from all working cone raises and whenever possible in small amounts 
that the contact surface between ore and soil remained more or less equal.

The maximum area of release is defined by a horizontal projection of a surface of contact between ore and soils at its distribution to an undercut level.

The analysis of experiences shows, that the increase in a corner of an inclination of a surface of contact (especially more than 50 degrees) negatively influences release indicators: the volume of the pure ore extracted prior to the beginning of dilution, decreases, and the volume of added barren rocks increases [4-8].

From methods of mining with a roof fall of system floor and a sublevel caving give the greatest losses and ore dilution. The least losses and dilution happen at a cutting of blocks in a cranch thanks to release of the most part of ore without contact with soils and their small size, and at its termination owing to horizontal contact at it of ore to soils.

The lowest qualitative and quantitative results of extraction are given by an extraction of blocks several lateral faces adjoining a goaf, on contact with which regular losses and dilution, from the beginning and till the end of release having the much bigger value, rather than taking place on contact to soils covering from above turn out.

Application of ways of preparation of blocks and mining methods basically depends from natural (power, a pitch angle, an ore hardness and adjacent strata, technical (the applied equipment) and technological (parameters of blocks) factors [9].

Cost of carrying out preparatory and access developments makes a considerable part of the cost price on mining method (from $33,0 \%$ to $56,2 \%$ ). In spite of the fact that from preparatory and access roads 5$10 \%$ of pure ore are extracted only, labour input of development workings occupies one of the main places, in general more than labour expenses on sublevel caving mining method.

The accepted way and preparation order, location and section of developments should correspond to following requirements: 1) to answer modern lines of development of technology of conducting mining operations; 2) to provide timely preparation of levels and blocks for preservation of a constant reserve of the reserves of ore prepared and ready to an extraction; 3) to promote a rock pressure decrease on developments within panel; 4) to lead to reduction of expenses on 
fastening and its repair; 5) to provide the maximum concentration of mining operations and intensive working of reserves of the block; 6) to raise productivity of stope; 7) to reduce labour input on drivages; 8) to provide on system as a whole the minimum cost price 1 t the extracted ore; 9) to plan possibility of application of the highefficiency chisel, loading and transport equipment; 10) to reduce ore losses in earth entrails; 11) to meet the requirements of sanitary-andhygienic conditions, safety of conducting preparatory and coal-face works.

One of conformity variants to these requirements are without the whole scheme of preparation of the blocks, which widespread.

The most important advantages of this way of preparation of blocks: the location under floor orts under an ore strata, and air orts in the adjacent block provides their stability at working of reserves of ore from a lying side to the trailing; expenses for a retimbering under level roads are reduced; good ventilation of stopes for all period of working of a sublevel remains; possibility of a selective mining of ore; sufficient heat-sink capacity of the ore chutes falling to each stope at working of reserves of the block; possibility for working of thick deposits in the conditions of a high rock pressure is created at an intensive actual mining of panels and secondary use of preparatory orts for massif drilling out by deep wells; necessity under floor over a pillar ort thanks to what losses are reduced is eliminated and quality of the extracted ore raises [10].

Lacks: complexity of conducting coal-face works on different horizons at increase in number of sublevels; necessity of strict observance of sequence of working of panels for blocks; increase in length of preparatory and access developments owing to carrying out additional under floor orts and increase at $5 \mathrm{~m}$ of length of drifts of scraping [11].

So, optimum parameters of the block at sublevel caving system are such which provide the greatest possible extraction of pure ore prior to the beginning of dilution, the minimum expenses for developments and the minimum production cost $1 \mathrm{t}$ ores. Optimum parameters of the block: a height of sublevel - $40 \mathrm{~m}$, length of the block - 60 $\mathrm{m}[12,13]$.

Statement of the problem. Thus, it is necessary to develop effective technology of working of deposits which is characterized by the 
big indicators of an ore mining. In turn the big indicators of an ore mining probably to receive with application of thick high-efficiency loading technics.

Statement of the material and the results. Pressure at an ore drawing from the brought down blocks located on depth of some hundreds of meters and more, considering from a surface, establishes the specific problems before analysis of dynamics of this process. At an ore drawing from the brought down blocks under leaning soils in the conditions of the raised rock pressure the expiration of a loose material from a vertical cylindrical vessel (release from bunkers) proceeds much more difficult, than. In the latter case problems of dynamics of release are reduced to definition of pressure of a stream of a loose material at its movement on the bottom and walls of a continuous part. A pressure source here is the stream of a moving loose material. In the conditions of underground ore mines constructive elements of the block and the brought down ore even before its release are under the static pressure which size in tens, time exceeds the pressure rendered by streams of brought down ore at its movement to final apertures.

Release of the brought down ore from the block or the panel causes redistribution of this pressure and can be in communication by this important action for a decrease of its size in a zone of coal-face works.

The main constructive element of caving systems subject to pressure, the bottom of the block and its wall in a zone of abutment vertical pressure is.

Horizontal pressure under influence, the so-called broken expansion, caused by formation of a crest and of interest at the expiration of loose bodies from silage towers, at release of the brought down ore recedes on a background. First, because calculation of walls of the block on durability is not necessary, and, secondly, because its size is insignificant in comparison with a vertical abutment pressure. As an ore drawing conduct, as a rule, from a series of final apertures of the block with formation of the general zone of breakage within all fulfilled area, sealing of ore under the influence of horizontal expansion at release from any aperture remains at inclusion in operation of the next apertures adjoining to it. 
Besides this phenomenon has no serious value for practice as lateral dilution at an ore drawing from the apertures adjoining on a goaf, is observed always in spite of the fact that sealing of dead rocks under the influence of horizontal tensions should take place.

It is all it is necessary to consider if to let out ore from one final aperture in delivery developments. But the situation can change, if release to make zones. Therefore in this case horizontal expansion will influence sealing of barren rocks and a decrease of lateral dilution that it will be possible to establish in the long term in laboratory conditions.

It is accepted to understand set of such practical actions for artificial regulation of size of character of increase and distribution of pressure to associates as pressure control under level roads which allow to provide stability of soils in one developments and on the contrary, uniform development of their caving in others. At an underground extraction of ore deposits this complex of actions consists in a choice of the rational sizes for the given concrete conditions and forms of developments, pillars and application of certain sequence of conducting coal-face works within the block and all deposit [14-16].

Transition of mining separate, located in a massif, blocks to wide application of systems of a floor caving, thus mass application of system has faced the whole complex of the phenomena which had no place at an extraction of the isolated blocks. The strengthened display of pressure concerns their number in slusher level developments, their complete destruction on the considerable areas, and on occasion destruction of an ore in place of the bottom and developments in it before the termination of a block undercutting.

On fig. 1 the model of release of the brought down ore from final apertures near which strain gauges for definition of value of loading on each strain gauge settled down is presented. The model is presented executed to scale M 1:100 with a forward glass wall. The distance between final apertures $-5 \mathrm{~m}$, diameter of final apertures $-2 \mathrm{~m}$. As a loose material is used martite ore from granules by metric structure $+1 \div-5 \mathrm{~mm}$. Height of the brought down layer in the panel $-40 \mathrm{~m}$. Depending on a location of strain gauges on the panel bottom accordingly change values of loading at an ore drawing.

From received a drawing (fig. 1) it is visible considerable nonuniformity in pressure distribution. The profile maximum is dis- 
lodged to a lying side and corresponds to pressure of a column of broken-down rocks.

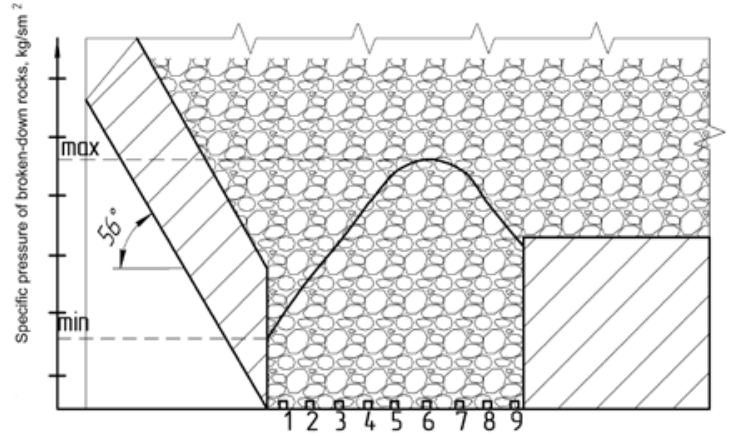

Fig. 1. Absolute values of loading on each strain gauge: $1-9-$ accordingly a location of strain gauges on the block bottom

Table 1

Results of laboratory researches

\begin{tabular}{l|c|c|c|c|c|c|c|c|c}
\hline Strain gauge number & 1 & 2 & 3 & 4 & 5 & 6 & 7 & 8 & 9 \\
\hline $\begin{array}{l}\text { Absolute values of load- } \\
\text { ing on each strain gauge, } \\
\mathrm{Kg} / \mathrm{cm}^{2}\end{array}$ & 20,8 & 26,0 & 31,0 & 41,5 & 47,5 & 53,3 & 49 & 48 & 39,2 \\
\hline
\end{tabular}

Pressure of broken-down rocks upon the block bottom at mining of thick steeply dipping deposits of the big prodeleting depends not only on depth of the mining operations, determining the elevation a column of broken-down rocks over the bottom, but also from the horizontal sizes of the block, from intensity of an ore drawing and sequence of operations in a mine field, defining the sizes and a location of the areas which are simultaneously being at a stage release.

Accepting certain parities between these parameters it is possible to regulate size of pressure of broken-down rocks, over a wide range keeping it at level considerably smaller weight of all columns of broken-down rocks.

The analysis of results of laboratory researches allows drawing following basic conclusions:

1. In the separate block located the long side an across the strike of a deposit, the size and character of distribution of pressure of brokendown rocks on the bottom basically depends on the sizes of the block 
along the strike. With increase in the size of the block along the strike increases not only absolute size of pressure, but also non-uniformity of its distribution. Thus the pressure maximum in the block located in a massif is mainly dated for points of a lying side, and in the block located between broken-down rocks - in the center.

2. Along with the horizontal sizes of the block considerable influence on size and character of distribution of pressure caused in the weight of broken-down rocks, renders intensity and an order of an ore drawing from the block. The increase in intensity of an ore drawing promotes pressure decrease on the bottom. Experiences, however, show that depending on width of the block and a massif condition on boundaries of the block release influence is shown variously. Thus the release order has extremely important role. At non-uniform release by the most widespread in practice, instead of a decrease increase of pressure upon those sites of the bottom in which limits an ore drawing rather is observed is less intensive.

In connection with non-uniform distribution of reserves of the brought down ore over ore chutes for preservation of horizontal contact between ore and leaning barren rocks more intensive release is made usually from ore chutes at a lying side. Thereof along with sharp pressure decrease in this part of the bottom pressure increase in the center of the block and at a trailing side is observed.

It occurs, because at an ort to the scheme of preparation of the bottom of inset horizon the storage drift usually settles down in soils of a lying side, therefore release occurs basically from first and second pair of final cone raises. From here more often, the air roadway where the ore drawing occurs not intensively (the big length of scraping) from the cone raises located around air roadway fails, and pressure upon bottom developments in this area first of all therefore increases.

The release role is especially great in the event that as vertical boundaries of the block broken-down rocks serve.

At a non-uniform and not intensive ore drawing from the block adjoining from two sides with broken-down rocks, pressure is considerable above, than in the block being in a massif, even in the event that from the block in a massif the ore drawing is not made.

3. Direct dependence of pressure on the bottom of the block which is in a stage of release, from the size is along the strike fair not only for the separate block, but also for a number of simultaneously developed 
blocks divided by intermediate pillars of sufficient width, presented by an ore in place or immobile broken grounds (fig. 2).

Under the specified conditions the size and character of distribution of pressure in each block is defined by its horizontal sizes and features in the release organization the same as and in the isolated block.

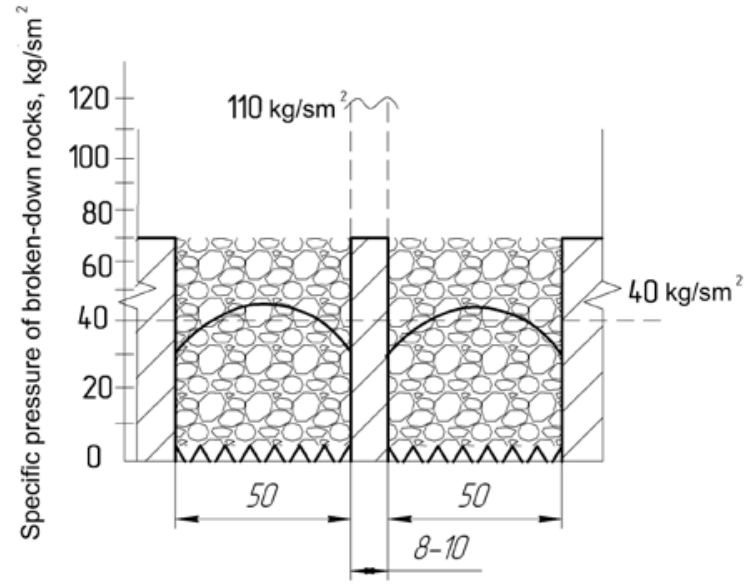

Fig. 2. Simultaneously developed blocks divided by intermediate pillars of sufficient width

Sharp change of pressure upon the top plane of intermediate pillars is observed.

The absolute size of average pressure upon an intermediate pillar is considerable and in 1,3-2,0 times of more pressure of all column of broken-down rocks, increasing with reduction of width of a pillar (fig. 3).

Loadings on a pillar are distributed non-uniformly, increasing from the middle to lateral planes.

Specific pressure of broken-down rocks at width of a pillar: $8 \mathrm{~m}$ $110 \mathrm{~kg} / \mathrm{cm}^{2} ; 10 \mathrm{~m}-100 \mathrm{~kg} / \mathrm{cm}^{2} ; 20 \mathrm{~m}-65 \mathrm{~kg} / \mathrm{cm}^{2} ; 30 \mathrm{~m}-52 \mathrm{~kg} / \mathrm{cm}^{2}$; $40 \mathrm{~m}-52 \mathrm{~kg} / \mathrm{cm}^{2}$. 


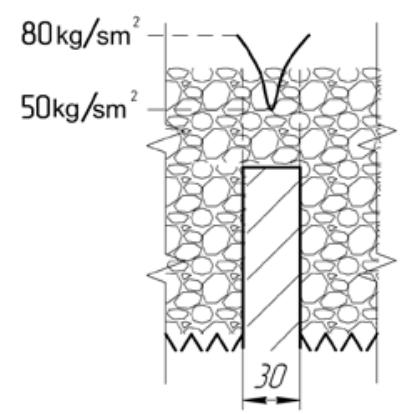

Fig. 3. Absolute size of average pressure upon an intermediate pillar

4. A role of pillars at a simultaneous ore drawing from a number of adjacent blocks can carry out also between the unitized sites presented by dabed brought down ore, release from which is not made. At non-uniform release at the expense of unloading of pressure upon bottom sites from which intensive release at present is made, the next volumes of broken-down rocks are in addition loaded. Thereof along with sharp pressure decrease on the sites of the bottom located at a lying side where intensive release is made, pressure in the block center considerably exceeds pressure of all columns of broken-down rocks $[17,18]$.

At an ore drawing there is a redistribution of pressure upon the block bottom. Over a final aperture from which made release, the loosening zone in communication, with what pressure within a zone is formed decreases. The zone radius in which there is an appreciable decrease of a rock pressure, depends on quantity of the let out ore (size of a dose of release) and can be defined under the formula

$$
R_{3}=\sqrt[3]{Q}+1,07 d
$$

where $Q$ - quantity of the ore let out from an aperture, $\mathrm{kg} ; d$-diameter of a final aperture, $m$.

Outside of a breakage zone the brought down ore condenses, and pressure upon the bottom increases. The gain size depends on initial pressure (before release from a final aperture) and from point distance in which gauging's of pressure to a final aperture from which release is made are made.

By experiences it is established, that after an ore drawing from an aperture $100-120 \mathrm{~m}^{3}$ on distance of $8-10 \mathrm{~m}$ from its axis pressure in- 
creases by $15-20 \%$, and on distance of $12-16 \mathrm{~m}-$ on $30-40 \%$ from initial. On more remote sites pressure increase gradually fades. Such laws of distribution of pressure are characteristic at release from one aperture.

At an in regular intervals-consecutive mode of an ore drawing from the brought down panels and blocks these laws continuously repeat in process of inclusion in operation of other apertures. Pressure change (a decrease or increase) occurs in steps in the expiration of ore from a final aperture, and its size changes from a minimum to a maximum in any point of the panel (block). The size of the minimum pressure does not depend on a location of an aperture within the panel (block) and (its) its sizes, and is defined only by quantity of the released ore [19-21].

At release from an aperture of ore of $20-30 \mathrm{~cm}^{3}$ the size of the minimum pressure is in limits $35-40 \mathrm{~g} / \mathrm{cm}^{2}$. The further ore drawing causes rock pressure slight increase in connection with increase in height of an ellipse of loosening. The size of the maximum pressure depends on the sizes of the panel (block), intensity and an ore drawing order.

The increase in length of the panel (block) an across the strike at invariable to width along the strike, intensity and an ore drawing order leads to growth of size of the maximum pressure upon the bottom of the panel (block). In panels in the size $24 \times 60 \mathrm{~cm}$ is pressure was on $25-27 \%$ more than in panels in the size $24 \times 30$ see especially sharply the size of the maximum pressure upon the panel bottom increases at increase in width of the panel along the strike.

Influence of an order of release on rock pressure size:

1. The most expedient from the point of view of rock pressure reduction is simultaneous release by echelons from an ore in place to the center of the area of the brought down panel and from the center to a goaf. At stepping release and an ore drawing echelons in a direction from the center to a goaf it made $0,82-0,85 \mathrm{H} \gamma$ - weight of a column of the material filled in in model [22]. 


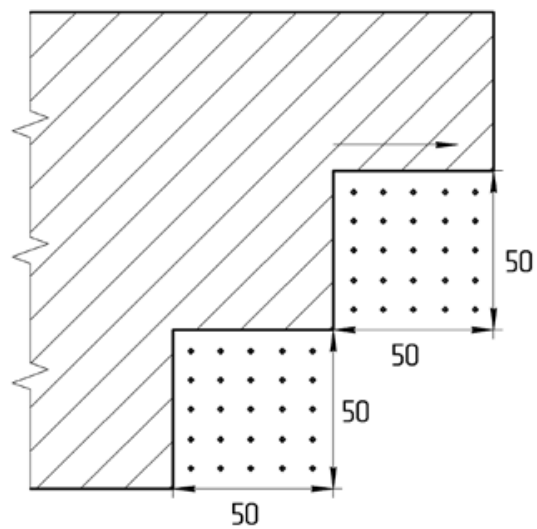

Fig. 4. Stepping ore drawing in a direction from the center to a goaf

2. At stepping release in a direction from a goaf and simultaneous release by echelons from the center to flanks it approximately on $10 \%$ more low.

The most expedient order of release in relation to first two on $26 \%$ more low also makes only $0,57 \mathrm{H} \gamma$.

Influence of a dose of release and intensity on rock pressure size:

1. At intensity increase, and, hence, and frequencies of an ore drawing from separate apertures pressure upon bottom developments decreases.

2. The pressure size, both minimum, and maximum with increase in a dose of release increases.

From the point of view of rock pressure size on the bottom simultaneous release from all final apertures of the panel when ore delivery is made by shuttle scrapers or conveyors is optimum. To the release beginning thanks to inclusion in operation of all final apertures of the panel there is a gradual breakage of ore on all area and pressure decrease on the bottom. Intensity of $\mathrm{g} / \mathrm{cm}^{2} ; \mathrm{t} / \mathrm{m}^{2}$; in a minute or a day for the second example $\left(I-0,02 \mathrm{~g} / \mathrm{cm}^{2} ; I I-0,04 \mathrm{~g} / \mathrm{cm}^{2} ; I I I-0,072 / \mathrm{cm}^{2}\right.$ $[23,24]$.

The deviation of size of the maximum pressure at in regular intervals-consecutive release to pressure at simultaneous release from all final apertures of the panel fluctuates from 1,48 to 1,63. 
Laboratory researches by definition of indicators of extraction of ore and rock pressure sizes (fig.5) on developments of the bottom of inset horizon at recommended technology of working of thick ore deposits of a Kryvyi Rih.

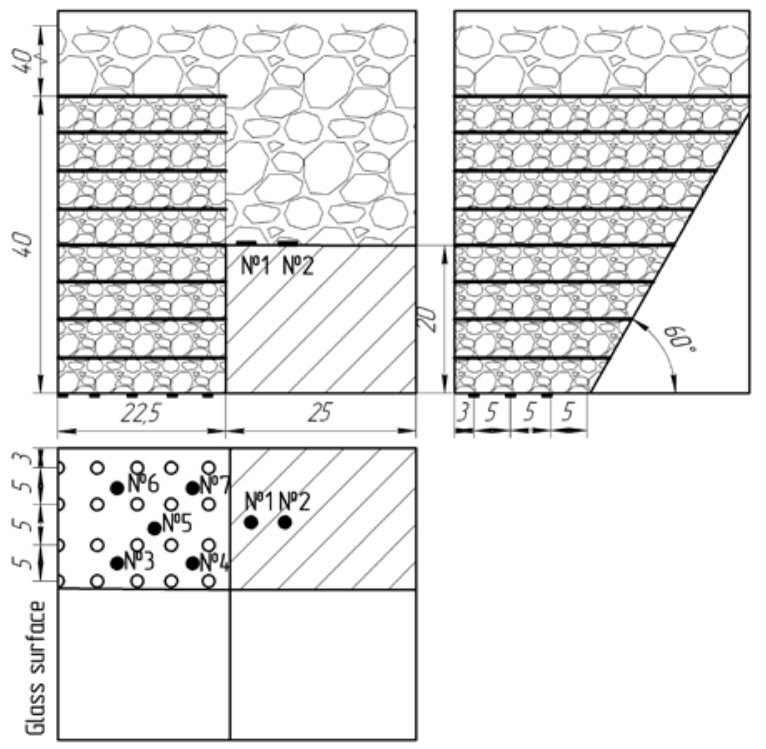

Fig. 5. Volume model for laboratory researches

The volume model is executed to scale M 1:100 with a forward glass wall (fig. 1). The distance between final apertures $-5 \mathrm{~m}$, diameter of final apertures $-2 \mathrm{~m}$. As a loose material is used martite ore from granules by metric structure $+1 \div-5 \mathrm{~mm}$. Leaning soils are presented to models by a crumb of granite from granules metric structure $+1 \div-5 \mathrm{~mm}$. Height of the brought down layer in the panel $-40 \mathrm{~m}$. Length of the panel which caves in along the strike $-25 \mathrm{~m}$, and in an across the strike - $20 \mathrm{~m}$.

For definition of pressure upon the bottom of inset horizon depending on a way and an ore drawing order in the panel bottom 5 strain gauges (fig. 1) take places. For definition of pressure upon a temporary pillar, a length along strike $-25 \mathrm{~m}$ and height $-20 \mathrm{~m}$ take places two strain gauges on the central line of a pillar on distance $5 \mathrm{~m}$ from territory of a pillar and $10 \mathrm{~m}$ between strain gauges on the central line. 


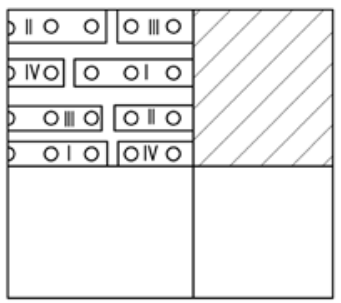

Fig.6

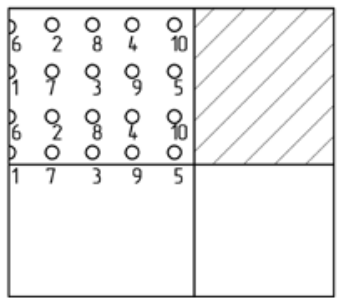

Fig. 8

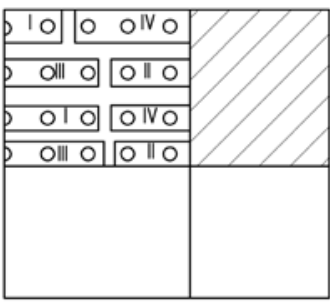

Fig. 7

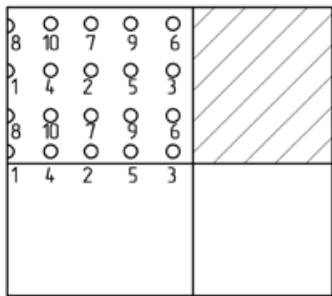

Fig. 9

Fig. 6, 7, 8, 9. Order of release of the brought down ore in the panel

On fig. 6, 7 the order of release of the brought down ore in the panel is shown at a recommended way of an ore drawing by in regular intervals-consecutive zones on 2-3 final developments. On fig. 8 and fig. 9 is shown an order of release of the brought down ore at an in regular intervals-consecutive mode of release by echelons in a direction from a lying side to a trailing side (fig. 9) and is stepping in a direction from a lying side to a trailing side (fig. 8).

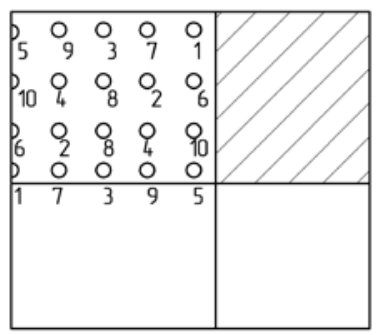

Fig.10

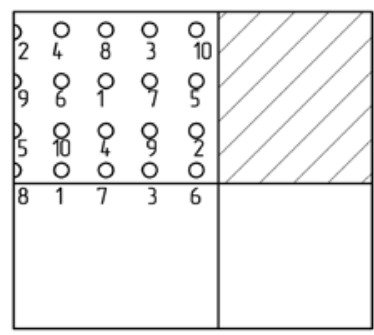

Fig.11

Fig. 10, 11. Order of release of the brought down ore in the panel 
On fig. 10 the order of release of the brought down ore in the panel serially through one final aperture prior to the beginning of dilution is shown.

On fig. 11 the chaotic order of release of the brought down ore in the panel is shown.

On above described ways of release the technology of an underground extraction systems of a sublevel caving of ore and adjacent strata with breaking of ore by fans of deep boreholes and delivery of broken ore by loading technics is recommended (fig. 12).
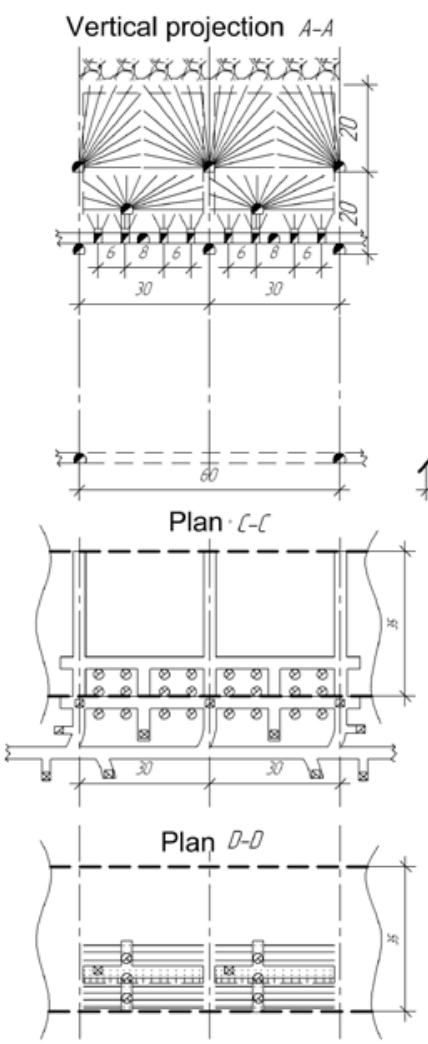

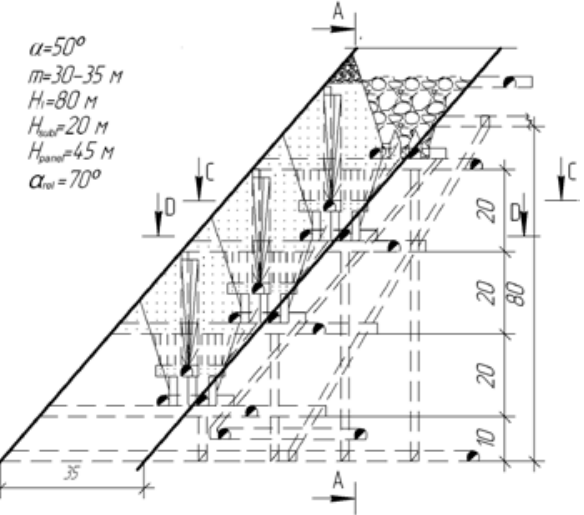

Section an across the strike

Fig. 12. Mining method of a sublevel caving of ore and adjacent strata with application of thick loading technics; $m$ - power of a deposit, $\mathrm{m} ; H_{l}$ - height of level, m; $\alpha$ - a deposit pitch angle, hailstones. 
Through $60 \mathrm{~m}$ drive orts-arrivals which have connection with haulage gate. Provided that the deposit pitch angle makes 50 degrees, deposit mining will be conducted by three sublevels, on each of which the vertical kerf is formed. Breaking is conducted by fans of deep ascending boreholes on vertical kerf.

On sublevels broken ore haul to ore chutes which incorporate to orts-arrivals. Further ore is overloaded with loading technics.

Conclusions. Thus further the recommended technology of mining leads to the general increase of intensity of working of sublevels. At the expense of increase of intensity of working of a sublevel efficiency of working of reserves as terms of their service decrease increases as a whole.

\section{References}

1. Tsarikovskiy, V.V., Grigorev, A.P. (2004). Prospects of application of various mining methods at underground extraction of ores in a Krivbass. Ore deposit mining, №85, 164-167.

2. Vasilchenkov, T.P. (1981). Influence of volume and the form of cutting on level of losses and ore dilution at mining method with ore breaking in the griped environment. Basic questions of complex development of deposits of firm minerals. IPKON AN SSSR, Moskva, 46-56.

3. Kolyada, Ye.I. (1980). Research, choice and mining of an effective variant of system of the sublevel caving providing a decrease of losses of ore in entrails. Krivoy Rog, 50-60.

4. Malahov, G.M, Bezuh, V.R., Petrenko, P.D. (1968). The theory and ore drawing practice. Nedra, Moskva, $311 \mathrm{p}$.

5. Anistratov, Yu.I., Zhabin, N.I. (1968). The theory and practice to a storage of mined rock inclined to caking. Nauka, Moskva.

6. Chernokur, V.R., Shkrebko, G.S., Shelegeda, V.I., (1992). Extraction of ores with a sublevel caving. Nedra, Moskva, 217 p.

7. Starikov, N.A. (1967). Mining methods of deposits. Metallurgizdat, Moskva.

8. Demidov, Yu.V., Aminov, V.N. (1991). Underground extraction of thick ore deposits. Nedra, Moskva, 204 p.

9. Stupnik, N., Kalinichenko, V., Kolosov, V., Pismennyi, S., \& Shepel, A. (2014). Modeling of stopes in soft ores during ore mining. Metallurgical and mining industry, 3, 32-36.

10. Stupnik, N.I., Kalinichenko, V.A., Hivrenko, O.Ya. \& et. al. (2011). Improvement of indicators of extraction of ore at system under a block caving. Krivoy Rog, NIGRI, 35, 136-142. 
11. Imenitov, V.R. (1984). Processes of underground mining operations at mining of ore deposits. Nedra, Moskva, 504 p.

12. Efremov, V.S. \& et. al. (1974). Preparation of blocks at mining of ore deposits. Nedra, Moskva, 208 p.

13. Rivkin, I.D., Voloshchenko, V.P., Maymin, L.R. (1964). Instructive instructions by definition of parameters of caving systems on conditions of a rock pressure manifestation with increase in depth of conducting mining operations at Krivbass mines. Krivoy Rog, NIGRI, 37.

14. Vloh, N.P. (1994). Pressure control on underground ore mines. Nedra, Moskva, $208 \mathrm{p}$.

15. Zubkov, A.V, Lelikov, V.P., Pyatkov, Yu.F. (1979). Pressure distribution in the bottom of the block during conducting coal-face works. Krivoy Rog, NIGRI, 6163 .

16. Rymarchuk, B.I., Shepel, O.L., Khudyk, M.V. (2017). Expediency of application of the vertical concentrated charges to decrease losses of ore on a lying wall of deposits. Naukovyi visnyk Natsionalnoho hirnychoho universytetu, 3, 32-37.

17. Baluta, A.M., Rivkin, I.D., Tohtuev, G.V. (1972). Expected geological conditions and rock pressure manifestation forms on deep horizons of mines of Krivorozhsky basin. Naukova dumka, Kiev, 45 p.

18. Rivkin, I.D., Tarapata, V.Ya., Halaydovskiy, N.Ya. (1969). Research of the is intense-deformed condition of hills in an extraction influence zone. Questions of perfection of mining methods with fall of level of mining operations. Krivoy Rog, NIGRI, 177-185.

19. Fursov, E.G., Kirichenko, V.M., Dyudin, Yu.K. \& et. al. (2005). Perfection of elements of caving systems. Gornyy zhurnal, 2, 34-38.

20. Strovskiy, V.E., Zhernyakov, Yu.I., Ignateva, M.I. \& et. al. (1984). Increase of efficiency of extraction of ores by underground way. Nedra, Moskva, $160 \mathrm{p}$.

21. Kalinichenko, V.A., Shepel, A.L. (2010). Theoretical and practical aspects of reduction of losses of ore on lying to a side of deposits. Naukovyi visnyk Natsionalnoho hirnychoho universytetu, 11-12, 40-43.

22. Kovshulya, A.A. (1962). Decrease of losses of rich ores Krivorozhsky mining basin iron. Akademiya nauk Ukrainy SSR, Kiev.

23. Lapshyn, O.O., Shapovalov, V.A., Khudyk, M.V., Shepel O.L. (2018). Industrial research on dust trapping efficiency by the fiber filter in aspiration shelters of reloading units. Naukovyi visnyk Natsionalnoho hirnychoho universytetu, 2, 101106.

24. Kalinichenko, V.A., Tarasyutin, V.M., Pismennyi, S.V., Shepel, A.L. (2015). About a question of a decrease of losses of ore on lying to a side of deposits. Girnychyi Visnyk Kryvorizkoho Natsionalnoho Universytetu, 99, 42-45. 